\title{
Rare coexistence of Tay-Sachs disease, coarctation of the aorta and grade $\mathrm{V}$ vesicoureteral reflux
}

\author{
Murat Ç. Karataşa (D), Havva Yazıcı ${ }^{b}$ (D), Ayşe E. Bozacı ${ }^{b}$ (D) Ebru Canda ${ }^{b}$, (D) Ertürk Levent ${ }^{\text {(D), }}$ \\ Sema K. Uçarb (D), Mahmut Çokerb (D)
}

\begin{abstract}
Tay-Sachs disease is a neurodegenerative inherited metabolic disease. There are four forms classified by the time of first clinical symptoms: infantile, late infantile, juvenile and adult. Infantile form has the poorest prognosis. Lately, different abnormalities which accompany metabolic disorders and affect the prognosis have been described.

We present an infant with Tay-Sachs disease accompanied by coarctation of the aorta and bilateral grade $\mathrm{V}$ vesicoureteral reflux (VUR). The patient was followed up in the outpatient clinic of Pediatric Cardiology. The abdominal ultrasonography showed pelvicalyceal ectasia; bilateral grade V VUR in voiding cystourethrography was found. This coexistence has not been previously reported. This case emphasizes that abnormalities in the neurological examination of cardiac postsurgical patients should not be underestimated because the opportunity to diagnose inborn errors of metabolism could be missed.

Key words: inborn errors of metabolism, lysosomal storage disorder, GM2 gangliosidosis, congenital abnormalities, aortic coarctation.

http: / / dx.doi.org/10.5546/ aap.2022.eng.e25
\end{abstract}

To cite: Karataş $\mathrm{MC}$, Yazıcı H, Bozacı AE, Canda E, et al. Rare coexistence of Tay-Sachs disease, coarctation of the aorta and grade $\mathrm{V}$ vesicoureteral reflux. Arch Argent Pediatr 2022;120(1):e25-e28.

\section{INTRODUCTION}

Tay-Sachs disease (TSD) is an autosomal recessive metabolic disease with GM2 ganglioside accumulation in lysosomes due to $\beta$-hexosaminidase A (HEXA) enzyme deficiency. It causes neurodegeneration and has four different clinical forms: infantile, late infantile, juvenile, and adult. ${ }^{1}$

a. Department of Pediatrics.

b. Division of Pediatric Metabolism and Nutrition.

c. Division of Pediatric Cardiology.

Ege University, İzmir, Turkey.

E-mail address:

Murat Ç. Karataş: muratcaglarkaratas@hotmail.com

Funding: None.

Conflict of interest: None.

Received: 12-11-2020

Accepted: 7-29-2021
The infantile form has the poorest clinical prognosis. First symptoms of this form, such as muscle weakness and hypotonia, occur around 4-6 months. Macrocephalia and exaggerated startle response in the physical examination are important signs. Death due to aspiration pneumonia usually occurs before the age of three. ${ }^{2}$ Late infantile and juvenile forms are usually seen between the ages of 2-10. In adult form, the existence of psychosis is notable together with pyramidal and extrapyramidal symptoms (dystonia, asteatosis, ataxia). ${ }^{1,2}$ In patients with suspicious anamnesis and physical examination, the diagnosis of TSD is established with abnormally low HEX A activity on enzyme testing and identification of biallelic pathogenic variants in HEXA gene by molecular genetic testing. So far there is no curative treatment for TSD. TSD is seen at a frequency of $1 / 320000$ in general population; in Ashkenazi Jews, the frequency is as $1 / 3900 .^{3}$

The frequency rate of congenital cardiac diseases is known to be approximately 0,8 $1,2 \%$ in live births. ${ }^{4}$ Coarctation of the aorta $(\mathrm{CoA})$ is a congenital, obstructive anomaly of the aortic lumen seen in 5-7 \% of all congenital heart diseases and has high mortality rates in undiagnosed patients. ${ }^{5}$

There are cardiac and renal abnormalities that accompany inherited metabolic diseases. For instance, some fatty acid oxidation defects show symptoms as serious cardiomyopathy. Carnitine metabolism disorders, Pompe disease, Fabry disease, GM1 gangliosidosis, congenital glycosylation defect, and some mitochondrial diseases are other metabolical diseases that may have cardiac effects. Glutaric aciduria type II may cause microcystic kidney. In patients who are diagnosed with galactosemia and hereditary fructose intolerance but don't have compliance with medication, proximal tubular dysfunction and renal failure may occur. Tubular dysfunction may occur in tyrosinemia type 1 and decrease in glomerular filtration rate and end-stage renal failure may be seen in cystinosis. ${ }^{6}$ However, cardiac and renal abnormalities accompanying TSD have not been previously described. 


\section{CASE REPORT}

The infant was born by C-section from a healthy mother, with a first-degree cousin marriage, in the $38^{\text {th }}$ week of pregnancy; birth weight was 3340 grams. He was admitted to the neonatal intensive care unit due to respiratory distress which started on the $8^{\text {th }}$ postnatal day. During the follow-up, tachypnea, $3 / 6$ systolic murmur, and increase in upper extremity blood pressures was detected in four extremity blood pressure measurements, and significant aortic narrowing (50 $\mathrm{mmHg}$ gradient) was identified in the echocardiography. Thorax angio CT showed $5 \mathrm{~mm}$ diameter ostium secundum atrial septal defect (ASD) and distal CoA (Figure 1). Therefore, the patient was operated in the $24^{\text {th }}$ day of life. The coarctation segment was excised and end-toend anastomosis was performed.

The patient was followed up in the outpatient clinic of Pediatric Cardiology. At 9-monthold the patient was admitted with motor and mental retardation. Pelvicalyceal ectasia (AP diameter: $6 \mathrm{~mm}$ on the right, $5 \mathrm{~mm}$ on the left) was detected by ultrasonography; bilateral grade $\mathrm{V}$ vesicoureteral reflux (VUR) was found in voiding cystourethrography. FISH (fluorescence in situ hybrisidation) and microarray analyses, performed due to $\mathrm{CoA}$ and accompanying renal pathology, were normal.

The patient had neuromotor developmental regression and a "cherry-red spot" was detected bilaterally in the macula in visual examination. In the physical examination, the patient was conscious. His head control was weak. He could no sit without support, movements were slow. His muscle tone was poor. Hyperacusia was identified. In laboratory examinations, blood biochemical analyses, and cerebrospinal fluid analyses (protein, glucose, lactic acid), were normal. In magnetic resonance imaging and spectroscopy (MRI and MRI-S) no significant anomaly was detected. Brainstem evoked

FIGURE 1. Thorax angio CT scanning; the aorta was hypoplasic distal to the arcus aorta gave its second branch; ascending aorta measured as $11 \mathrm{~mm}$; proximal arcus aorta measured as 9,1 $\mathrm{mm}$ (3D 4 projection), and distal hypoplasic segment was $5 \mathrm{~mm}$ diameter (3D 1 projection). In the aorta, advanced coarctation was distal to the origin of the left subclavian artery (arrow). The diameter fell to $1.1 \mathrm{~mm}$ (3D 2 projection). Descending aorta diameter was measured as $7.5 \mathrm{~mm}$ (3D 3 projection)

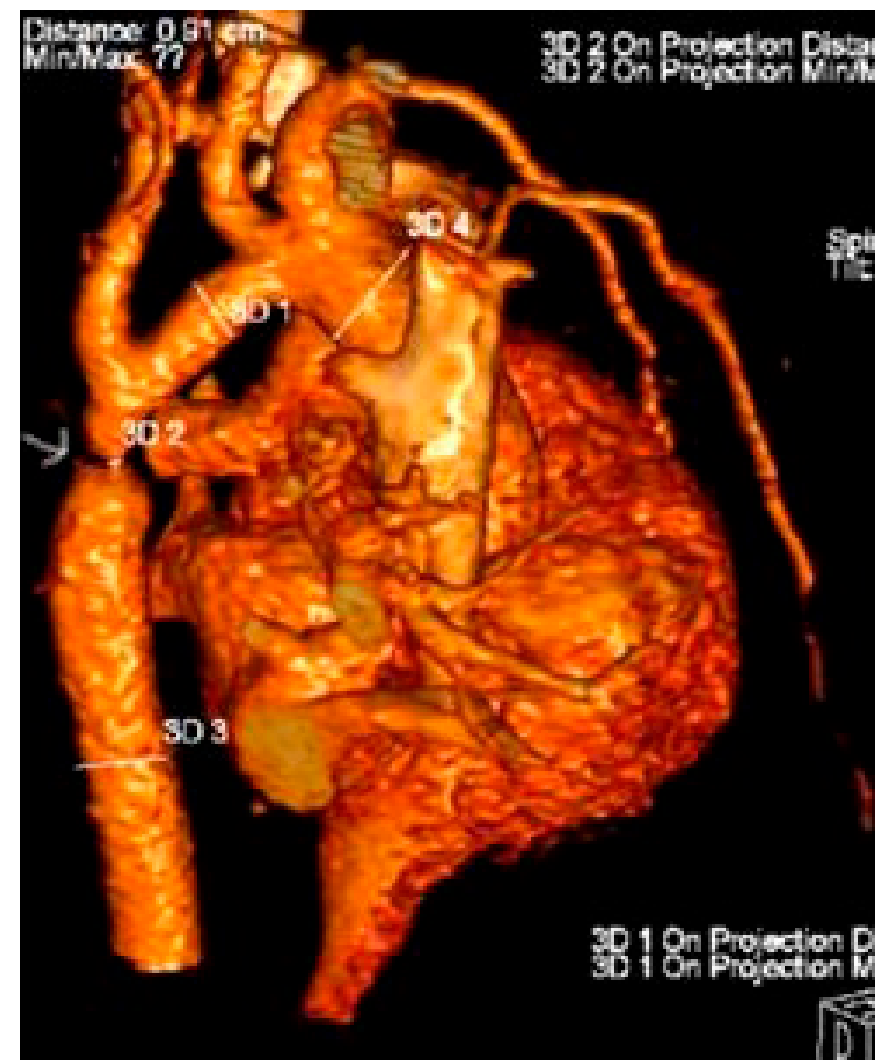


response audiometry and electromyography which were performed for neurophysiological evaluation were normal. However, bilateral partial conduction disturbance was observed in visually evoked potential.

The patient was evaluated through his history and physical examination findings for suspicion of neurometabolic diseases. Significantly low HEXA enzyme levels $(0.5 \mathrm{nmol} / \mathrm{ml}$ in dry blood, normal: 7-70) were detected. In molecular analysis, homozygote c.1361G >A/p.Gly454Asp mutation in HEXA gene was identified. The mutation was confirmed by Sanger sequencing from parents. Both of the parents were heterozygous.

\section{DİSCUSSİON}

The name Tay-Sachs was attributed to the British ophthalmologist Warren Tay, who first defined the red spots on the retina, one of the symptoms of the disease, in 1881, and to the American neurologist Bernard Sachs, who first reported the changes in cellular status during the disease in 1887. The disease is more common in East Europe and Ashkenazi Jews. ${ }^{7}$ Children with this disease spend the first months of their lives normally; however, after about the end of the $6^{\text {th }}$ month, symptoms develop and the disease causes progressive intelligence loss, dementia, avoidance of eye contact, exaggerated startle response, loss of hearing, dysphagia, vision loss, the cherryred spot in the retina, and spasticity. Myoclonic seizures frequently occur in the first year. Focal and generalized seizures may also be observed. TSD patients die mostly before the age of five. In this disease, in which curative treatment is not available, supportive treatment is essential. These treatments include sufficient diet and methods which may keep the airways open.

Late-onset TSD, which is a rarer form, occurs in the early 20s with symptoms such as difficulty in walking and progressing neurological disorders. ${ }^{8}$ Nowadays, new treatment models are being investigated. There are clinical studies on substrate reduction therapy with miglustat and hematopoietic stem cell transplantation. There are also gene therapy methods that are in development. ${ }^{9}$ The use of substrate reduction therapy (miglustat) was shown to prevent the accumulation of GM2 ganglioside in the brain of model mice with TSD. ${ }^{10}$ However, there are case reports reporting that the use of miglustat did not stop the progression of neurological dysfunction. ${ }^{11}$
CoA has high mortality rates in undiagnosed patients. It is usually seen as sporadic and is more common in males. CoA is divided into two groups: critical CoA (approximately $60 \%$ of all coarctations) that shows symptoms within two months postpartum and leads to death if left untreated, and asymptomatic CoA developing symptoms with upper extremity hypertension in later years. Patients with untreated CoA have a high risk of mortality and morbidity. While 50$70 \%$ of the cases have a bicuspid aortic valve, other accompanying congenital abnormalities include tubular hypoplasia of arcus aorta, patent ductus artriosus, ventricular septal defect and atrial septal defect. 5,12 The electrocardiogram shows signs of right ventricular hypertrophy, contrary to expectations. Recent studies in Scandinavia have shown that at least $50 \%$ of newborns with CoA are discharged without a diagnosis. Another study showed that $27 \%$ of patients with CoA died within the mean of 17 days without diagnosis. ${ }^{13}$ The easiest way to diagnose $\mathrm{CoA}$ is by evaluating the femoral pulses of all newborns between the $3^{\text {rd }}$ and $7^{\text {th }}$ days to refer them to the hospital for further examination when necessary. ${ }^{12}$

Our patient with grade V VUR, CoA, and secundum ASD identified in the neonatal period, was genetically and enzymatically diagnosed with TSD as a result of workups performed with the addition of ophthalmological findings and neurological symptoms in the follow-up.

Some cases which have additional diseases accompanying TSD were reported. Acar S. et al., presented two patients, who were proven to genetically have TSD and who developed central early puberty in the follow-up. ${ }^{14}$ Ahmed NR. et. al, presented an infantile TSD case with a one-sided choroid coloboma. ${ }^{15}$ However, in the literature review, the coexistence of TSD and CoA has not been described before. Whether this coexistence is coincidental or ganglioside metabolism has a role in this coexistence has not yet been clarified. We emphasize that abnormalities in the neurological examination of cardiac postsurgical patients should not be underestimated. If not, the opportunity to diagnose the inborn errors of metabolism could be missed.

\section{REFERENCES}

1. Pastores GM, Hughes DA. Non-neuronopathic lysosomal storage disorders: disease spectrum and treatments. Best Pract Res Clin Endocrinol Metab. 2015; 29(2):173-82.

2. Pastores GM, Maegawa GHB. Clinical neurogenetics: neuropathic lysosomal storage disorders. Neurol Clin. 2013; 
31(4):1051-71.

3. Lew RM, Burnett L, Proos AL, Delatycki MB. Tay-Sachs disease: current perspectives from Australia. Appl Clin Genet. 2015; 8:19-25.

4. Marelli AJ, Mackie AS, Ionescu-Ittu R, Rahme E, Pilote L. Congenital heart disease in the general population: changing prevalence and age distribution. Circulation. 2007; 115(2):163-72

5. Aboulhosn J, Child JS. Left ventricular outflow obstruction: subaortic stenosis, bicuspid aortic valve, supravalvar aortic stenosis, and coarctation of the aorta. Circulation. 2006; 114(22):2412-22

6. Levy PA. Inborn errors of metabolism; part 1 overview. Pediatr Rev. 2009; 30(4):131-7.

7. Fernandes JA Filho, Shapiro BE. Tay-sachs disease. Arch Neurol. 2004; 61(9):1466-8.

8. Vanier MT, Caillaud C. Disorders of sphingolipid metabolism and neuronal ceroid-lipofuscinoses. In: Saudubray JM, van den Berghe G, Walter JH (eds). Inborn Metabolic Diseases. Heidelberg: Springer; 2012. Págs.555-77.
9. Solovyeva VV, Shaimardanova AA, Chulpanova DS, Kitaeva KV, et al. New Approaches to Tay-Sachs Disease Therapy. Front Physiol. 2018; 9:1663.

10. Bembi B, Marchetti F, Guerci VI, Ciana G, et al. Substrate reduction therapy in the infantile form of Tay-Sachs disease. Neurology. 2006; 66(2):278-80.

11. Maegawa GHB, Banwell BL, Blaser S, Sorge G, et al. Substrate reduction therapy in juvenileGM2 gangliosidosis. Mol Genet Metab. 2009; 98(1-2):215-24.

12. Hoffman JI. The challenge in diagnosing coarctation of the aorta. Cardiovasc J Afr. 2018; 29(4):252-5.

13. Chang RKR, Gurvitz M, Rodriguez S. Missed diagnosis of critical congenital heart disease. Arch Pediatr Adolesc Med. 2008; 162(10):969-74.

14. Acar S, Arslan N, Paketçi A, Okur TD, et al. Presentation of central precocious puberty in two patients with TaySachs disease. Hormones (Athens). 2018; 17(3):415-8.

15. Ahmed NR, Tripathy K, Kumar V, Gogia V. Choroidal coloboma in a case of Tay-Sachs disease. Case Rep Ophthalmol Med. 2014; 2014:760746. 